네을

Take a deep dive into the business of transplantation!

\section{Digital Kidney \& Liver}

Transplant

Financial Bootcamp

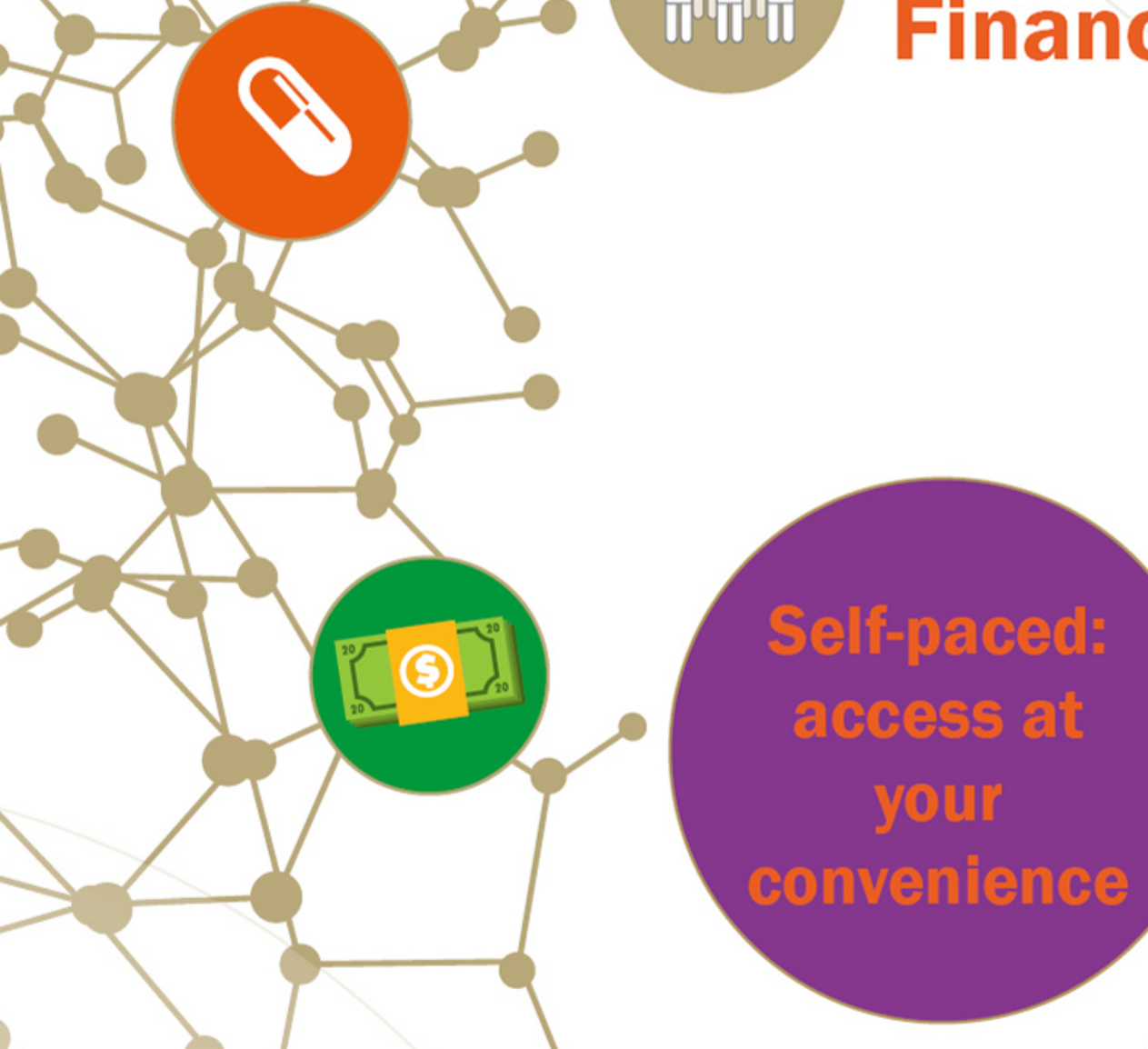

American Society of Transplant Surgeons

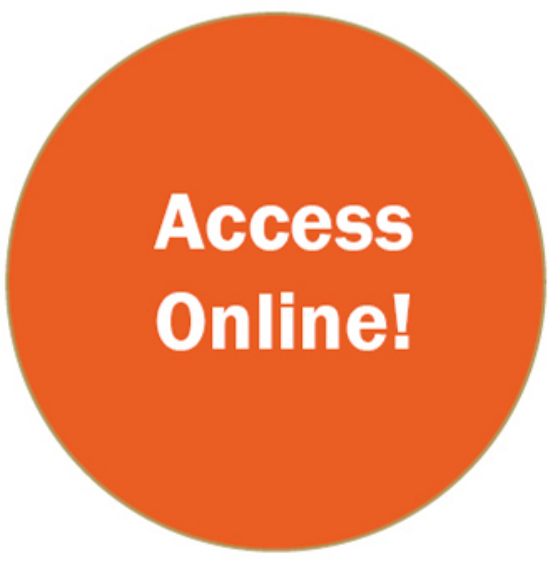

GONVEDAPCF

Register at ASTS.org/bootcamps 


\title{
Comprehensive analysis of the immunomodulatory effects of rapamycin on human T cells in graft-versus-host disease prophylaxis
}

\author{
Grégory Ehx $^{1}$ ( ) | Caroline Ritacco ${ }^{1}$ | Muriel Hannon ${ }^{1}$ | Sophie Dubois ${ }^{1}$ | Loic Delens ${ }^{1}$ | \\ Evelyne Willems $^{2}$ | Sophie Servais ${ }^{1,2}$ | Pierre Drion ${ }^{3}$ | Yves Beguin ${ }^{1,2}$ | Frédéric Baron ${ }^{1,2}$
}

${ }^{1}$ Groupe Interdisciplinaire de Génoprotéomique Appliquée (GIGA)-I ${ }^{3}$, University of Liège, Liège, Belgium

${ }^{2}$ Department of Medicine, Division of Hematology, $\mathrm{CHU}$ and University of Liège, Liège, Belgium

${ }^{3}$ Experimental Surgery, GIGA-R \& Credec, University of Liège, Liège, Belgium

\section{Correspondence}

Grégory Ehx, Groupe Interdisciplinaire de Génoprotéomique Appliquée (GIGA)-1 $1^{3}$, University of Liège, Liège, Belgium.

Email: g.ehx@uliege.be

Funding information

National Fund for Scientific Research (FNRS), Grant/Award Number: T.0069.15 and T.0016.20; Belgian Fondation contre le cancer, Grant/Award Number: FAF-C/2016/889; Leon Fredericq Fund; Anti-Cancer Center at the University of Liège; Fonds Wetenschappelijk Onderzoek (FWO)
Graft-versus-host disease (GVHD) is a major cause of toxicity after allogeneic hematopoietic cell transplantation (allo-HCT). While rapamycin (RAPA) is commonly used in GVHD prophylaxis in combination with a calcineurin inhibitor (CNI), the understanding of its mechanism of action on human T cells is still incomplete. Here, we performed an extensive analysis of RAPA effects on human T cells in a humanized mouse model of GVHD, in ex-vivo T cell cultures and in patients given RAPA plus tacrolimus as GVHD prophylaxis after nonmyeloablative allo-HCT. We demonstrate that RAPA mitigates GVHD by decreasing $T$ cell engraftment and differentiation, inhibiting $C D 8^{+} \mathrm{T}$ cell activation and increasing the long-term IL-2 secretion, thereby supporting regulatory $T$ cell (Treg) proliferation. In contrast, graft-versus-leukemia effects were not abrogated, as RAPA-treated T cells had increased resistance to apoptosis and retained their effector function and proliferative capacity upon re-stimulation. Importantly, we found that RAPA impact on Treg and CD8 ${ }^{+} \mathrm{T}$ cells was closely dependent upon IL-2 signaling and that therapeutic options interfering with IL-2, such as calcineurin inhibitors, antagonize the IL-2-dependent promotion of Treg mediated by RAPA. Our results suggest that RAPA immunological efficacy could be improved in combination with drugs having possible synergistic effects such as the hypomethylating agent 5-azacytidine.

\section{KEYWORDS}

basic (laboratory) research/science, bone marrow/hematopoietic stem cell transplantation, flow cytometry, graft-versus-host disease (GVHD), graft-versus-leukemia (GVL)/graft versus tumor, hematology / oncology, immunosuppressant - mechanistic target of rapamycin: sirolimus, immunosuppression/immune modulation, T cell biology, translational research/ science

\section{1 | INTRODUCTION}

Allogeneic hematopoietic cell transplantation (allo-HCT) remains the most effective treatment option for many patients suffering from hematological malignancies. ${ }^{1}$ However, its success is limited by the development of graft-versus-host disease (GVHD), which is caused by donor $T$ cells reacting against host foreign antigens. ${ }^{2}$ Despite standard prophylaxis regimens, GVHD still develops in

Abbreviations: allo-HCT, allogeneic hematopoietic stem cell transplantation; CNI, calcineurin inhibitor; GVHD, graft-versus-host disease; IL, interleukin; NSG, NOD-scid IL-2R $\gamma$ null; mTOR, mechanistic target of rapamycin; PBMC, peripheral blood mononuclear cell; RAPA, rapamycin; Tconv, conventional T cell; TCR, T cell receptor; Treg, regulatory T cell. Grégory Ehx and Caroline Ritacco are co-first authors. 
$20 \%-70 \%$ of allo-HCT recipients. ${ }^{3}$ Further, current approaches of GVHD prophylaxis also impair graft-versus-leukemia (GvL) effects. $^{4,5}$

Rapamycin (RAPA) is an inhibitor of mTOR (mechanistic Target of Rapamycin), a serine/threonine kinase integrating environmental cues and regulating cell growth. ${ }^{6,7}$ In T cells, mTOR is activated in response to $T$ cell receptor (TCR), costimulatory molecules and various cytokine receptors (including IL-2R, IL-7R, and IL-15R) signaling. Consequently, inhibiting mTOR reduces $\mathrm{T}$ cell activation, proliferation and differentiation. ${ }^{8,9}$ Further, RAPA was also shown to promote regulatory $\mathrm{T}$ cells (Treg, defined as $\mathrm{CD} 4^{+} \mathrm{CD} 25^{+} \mathrm{FOXP} 3^{+}$) expansion and function in mice ${ }^{10,11}$ and in humans ${ }^{12,13}$ while inhibiting $\mathrm{CD}^{+}$conventional T cells (Tconv). These effects could be attributed to the preferential use of the STAT5 pathway by Treg in response to IL-2 (since the mTOR pathway is constitutively inhibited in Treg ${ }^{14}$ ) while IL-2 signaling is also mediated by the mTOR pathway in Tconv. ${ }^{10,11,14}$

Due to its immunomodulatory properties, RAPA is increasingly used as GVHD prophylaxis. ${ }^{15}$ However, clinical trials have yielded contrasted results about its beneficial effects. ${ }^{16}$ Therefore, we provide here an extensive and transversal analysis of RAPA immunomodulatory properties that could be used as scaffold for the design of future trials aiming to improve RAPA clinical efficacy.

\section{2 | MATERIALS AND METHODS}

All experimental and statistical procedures are in online Appendix S1.

\section{3 | RESULTS}

\section{1 | RAPA mitigates GVHD, increases the CD4/ $C D 8$ ratio, reduces the proliferation and increases $T$ cell resistance to apoptosis}

To investigate the impact of RAPA on human T cells in GVHD, we transplanted NSG mice with human peripheral blood mononuclear cells (PBMCs) $^{17,18}$ and administered RAPA every $24 \mathrm{~h}$ for 21 days. Higher survival rates and lower GVHD scores were observed in treated than in control mice (Figure 1A,B). Similar results were observed in a repetition of this experiment (Figure S1A,B). RAPA reduced engraftment levels but increased $\mathrm{CD} 4^{+} / \mathrm{CD}^{+} \mathrm{T}$ cell ratios in all examined organs (Figure 1C,D). We therefore assessed the impact of RAPA on apoptosis and proliferation of human $T$ cells (the only cell population to engraft in NSG mice following PBMC infusion ${ }^{19,20}$ ). ANNEXIN V binding assays showed that the treatment significantly reduced the frequency of apoptotic T cells in spleen (Figure S2). Interestingly, T cell BCL-2 expression was increased in treated mice, suggesting that RAPA promotes resistance to apoptosis through $\mathrm{BCL}-2$ (Figure $1 \mathrm{E}$ ).

To determine the impact of RAPA on proliferation, we in fused NSG mice with CFSE-loaded PBMCs and found that RAPA significantly decreased $\mathrm{CD}^{+}$and $\mathrm{CD}^{+} \mathrm{T}$ cell proliferation (Figure S3). HLA-DR expression was also reduced in treated mice, suggesting that RAPA inhibits T cell proliferation through the prevention of their activation (Figure 1F). Importantly, at day 25 after PBMC transplantation, the KI67 expression by human T cells was lower in RAPA than in control mice but the amplitude of this difference was greater for $C D 8^{+}$than for $C D 4^{+} T$ cells, suggesting a higher antiproliferative effect of RAPA on $\mathrm{CD} 8^{+} \mathrm{T}$ cells (Figure 1G). Therefore, our data show that RAPA decreased engraftment through the reduction of human $\mathrm{T}$ cell proliferation and increased the $C D 4 / C D 8$ ratio through a higher anti-proliferative impact on $\mathrm{CD}^{+}$than on $\mathrm{CD}^{+} \mathrm{T}$ cells.

\subsection{RAPA decreases the differentiation of T cells}

Considering the link between the activation and effector functions of $T$ cells, we investigated the impact of RAPA on T cell differentiation. RAPA decreased the expression of GRANZYME $B$ and PERFORIN-1 as well as respectively decreased and increased the frequency of effector and naive $\mathrm{CD} 8^{+} \mathrm{T}$ cells (Figure $1 \mathrm{H}, \mathrm{I}$ ). In $\mathrm{CD} 4^{+}$ $T$ cells, RAPA respectively decreased and increased the frequency of effector memory and central memory cells (Figure 1I). In addition, RT-qPCR analyzes of T-bet and ROR $\gamma$, the specific transcription factors of Th1 and Th17 lineages, evidenced reduced levels of both transcripts in treated animals (Figure 1J). Accordingly, there was a dramatic reduction of IFN- $\gamma$, TNF- $\alpha$ (two cytokines mainly secreted by Th1 cells) and IL-17 (mainly secreted by Th17 cells) concentrations in RAPA mice serum (Figure 1K). In contrast, both transcript levels and serum concentration of IL-2 were increased in treated mice. Altogether, these results show that RAPA reduces the differentiation and effector function of T cells while increasing IL-2 levels.

\section{3 | RAPA preserves GvL effects and T cell effector function upon re-stimulation}

The reduction of $\mathrm{T}$ cell differentiation and proliferation combined with the reduction of cytotoxic T cell frequency by RAPA prompted us to ask whether GvL effects might be abrogated by the treatment. NSG mice were therefore transplanted with acute myeloid leukemia (AML) THP-1-luc cells, ${ }^{18}$ and received human PBMCs or not in combination with RAPA or not. RAPA treatment, only when combined with PBMCs transplantation, significantly ameliorated the survival (Figure 2A). Accordingly, PBMCs+RAPA mice presented a significantly lower tumor burden than those having received THP-1 alone or THP-1+RAPA (Figure 2B). As this showed that RAPA preserves the anti-tumor function of human $T$ cells, we investigated whether they retained their effector and proliferative functions after treatment by sorting human $\mathrm{CD} 45^{+}$cells from the spleen of mice having received RAPA or not and secondarily transplanting them in new NSG mice (not transplanted before). $\mathrm{CD} 45^{+}$cells isolated from RAPA-treated 
(A)

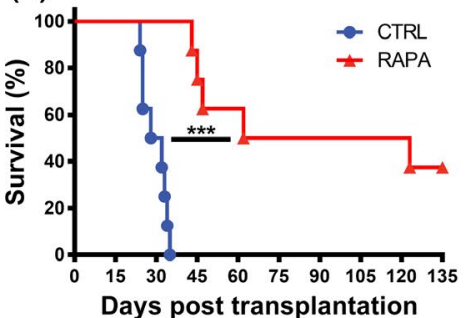

(B)

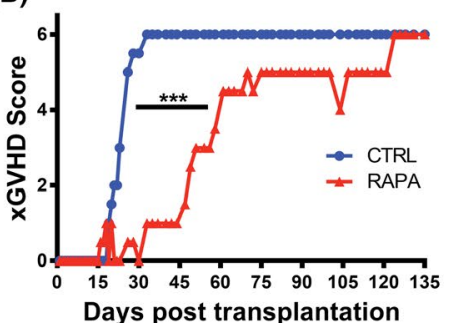

(C)

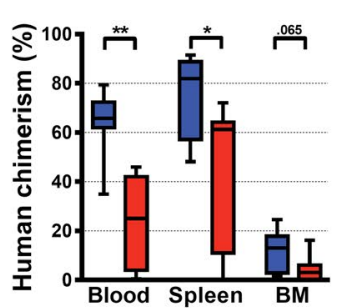

(D)

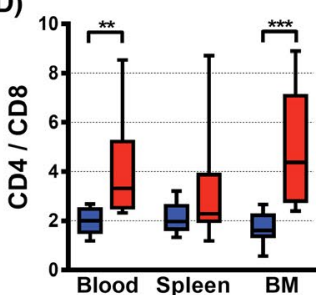

(E)

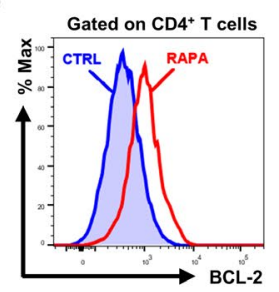

(H)

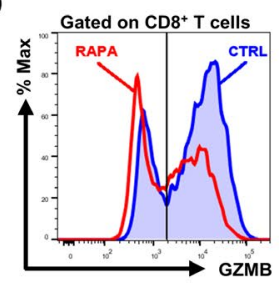

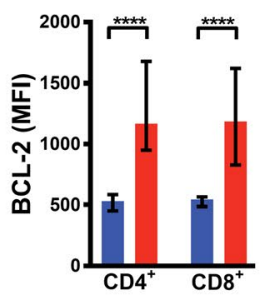

(F)

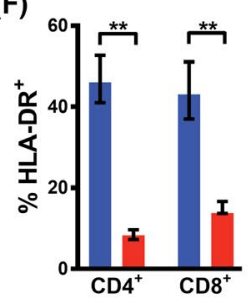

(G)

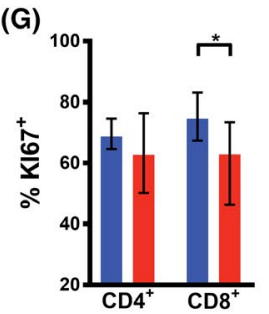

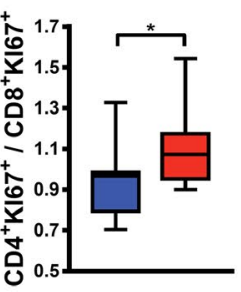

(I)
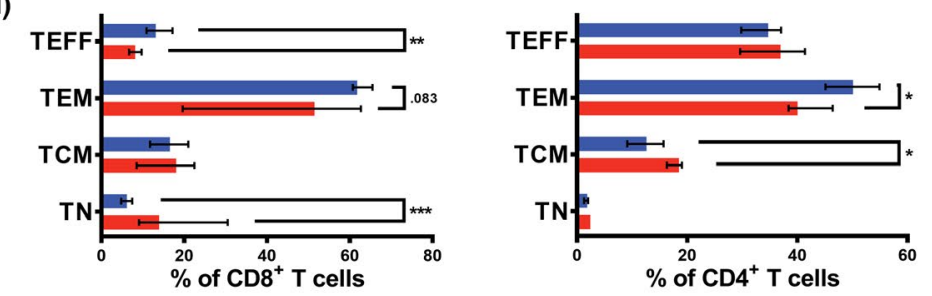

(J)

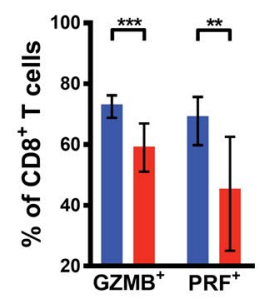

(K)
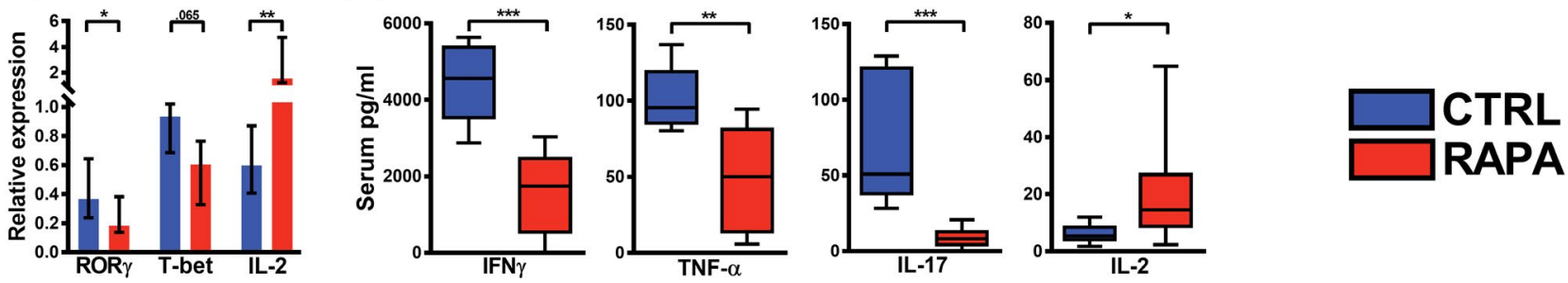

FIGURE 1 RAPA mitigates xenogeneic GVHD. NSG mice were transplanted with $2 \times 10^{6}$ human PBMCs, $24 \mathrm{~h}$ after $2.5 \mathrm{~Gy}$ TBI, and were treated with RAPA or not. Mice were either monitored for survival and GVHD score (A,B) or sacrificed at day 7 (F) or 25 (C-E and G-K) for flow cytometry (C-I), RT-qPCR (J) or bioplex (K) analyzes of their organs (indicated in C,D and spleen in E-J). (A,B) Survival curve and scoring of median xeno-GVHD in two groups of mice transplanted with two different healthy donors ( $n=16 /$ donor and $n=8 /$ condition). (C,D) FACS analyses of human chimerism (calculated as the ratio of human $\mathrm{CD} 45^{+}$cells vs. murine+human $\mathrm{CD} 45^{+}$cells) and $\mathrm{CD} 4^{+} / \mathrm{CD} 8^{+}$ T cell ratio in indicated organs. (E) Representative FACS data (left panel) and comparison (right panel) of BCL-2 expression by indicated T cells. (F) Comparison of HLA-DR expression by indicated T cells. (G) Comparison of KI67 expression by indicated T cells (left panel) and comparison of $\mathrm{CD}^{+}{ }^{+} \mathrm{KI} 67^{+} / \mathrm{CD}^{+} \mathrm{KI} 67^{+}$ratio (right panel). (H) Representative FACS data of granzyme B (GZMB) expression (left panel) and comparison of GZMB and Perforin-1 (PRF) expression by CD8 ${ }^{+} \mathrm{T}$ cells (right panel). (I) Frequencies of effector (TEFF, CD27 CD45RA'), effector memory (TEM, CD27 $7^{+} \mathrm{CD} 45 \mathrm{RA}^{-} \mathrm{CD} 62 \mathrm{~L}^{-}$), central memory (TCM, CD27 $7^{+} \mathrm{CD} 45 \mathrm{RA}^{-} \mathrm{CD} 62 \mathrm{~L}^{+}$), and naive (TN, $\mathrm{CD}^{2} 7^{+} \mathrm{CD} 45 \mathrm{RA} \mathrm{A}^{+}$) subsets in $\mathrm{CD}^{+}$(right panel) and $\mathrm{CD}^{+}$(left panel) T cells. (J) Comparison of ROR $\gamma$ and T-bet expression, normalized on human TBP gene expression. (K) Comparison of indicated cytokine serum concentration. Data from $\mathrm{C}$ to $\mathrm{K}$ show median values with either interquartile range ( $\mathrm{E}-\mathrm{G}$ and $\mathrm{H}-J)$ or 5-95 percentile (C,D, G and K) of 8-13 mice/condition $\left({ }^{*} p \leq .05,{ }^{* *} p<.01,{ }^{* * *} p<.001,{ }^{* * * *} p<.0001\right)$

animals preserved their capacity to mediate lethal GVHD while mice receiving $T$ cells from control animals survived beyond day 60 (Figure S4A). This difference was associated with lower $\mathrm{T}$ cell engraftment in secondarily transplanted mice given cells from control mice versus those given cells from RAPA-treated mice (Figure S4B). Altogether, these data show that RAPA does not hamper T cell antitumor activity and preserves their proliferative capacity and effector function upon re-stimulation.

\section{4 | RAPA increases the IL-2-dependent Treg proliferation}

The Treg-promoting effects of RAPA have been extensively described in the literature. ${ }^{12,14,21,22}$ Accordingly, Treg frequencies were significantly increased by RAPA in our GVHD model, either when defined as $\mathrm{CD} 4^{+} \mathrm{CD} 25^{\text {high }} \mathrm{FOXP} 3^{+}$or $\mathrm{CD} 4^{+} \mathrm{CD} 25^{\text {high }} \mathrm{CD} 127^{\text {low }} \mathrm{FOXP} 3^{+}$ (Figure $3 \mathrm{~A}$ ). Interestingly, and in opposition with our observations 
FIGURE 2 RAPA preserves graftversus-leukemia effects. NSG mice were transplanted with $1 \times 10^{6} \mathrm{THP}-1$-luc cells together or not with $2 \times 10^{6}$ human PBMCs, $24 \mathrm{~h}$ after $2.5 \mathrm{~Gy}$ TBI. Mice were either treated or not with RAPA $1 \mathrm{mg} / \mathrm{kg}$ and survival $(A)$ and bioluminescence $(B)$ were monitored ( $n=8-10$ mice/group). Actual images of one representative mouse from each group are shown with Y-axis indicating photon flux (photons/ sec) measured from the ventral view with a region of interest drawn over the entire body of each mouse. Right panels show the comparison of bioluminescence between groups. Plots in B show median values with interquartile range $\left({ }^{*} p \leq .05\right.$, $\left.{ }^{* *} p<.01,{ }^{* * *} p<.001,{ }^{* * * *} p<.0001\right)$

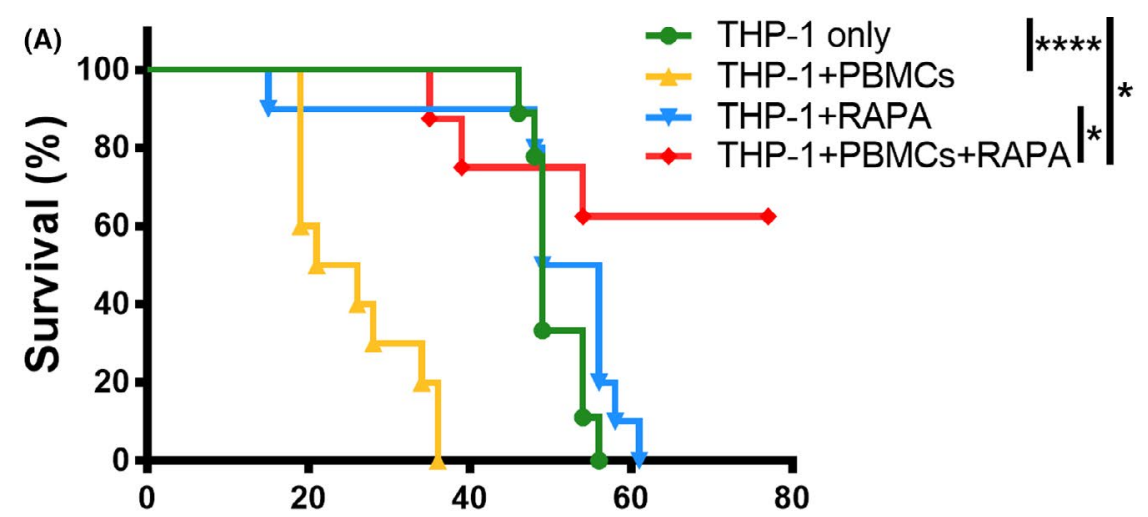

Days post transplantation

(B)

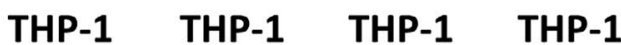
PBMCs PBMCs
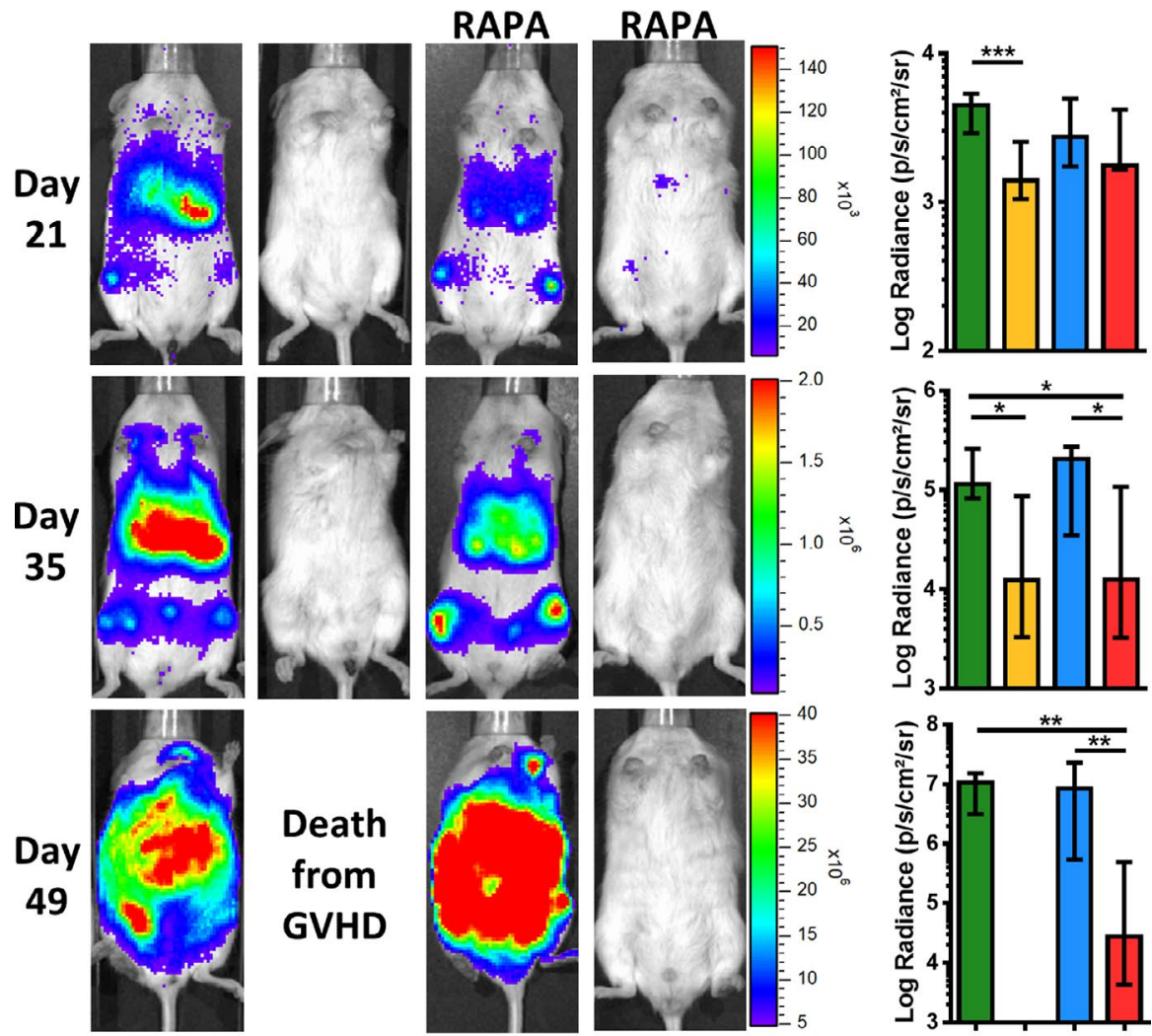

made on total $\mathrm{CD} 4^{+} \mathrm{T}$ cells, Treg proliferation was higher in treated mice (Figure 3B). Because Treg proliferation is closely dependent on IL-2, ${ }^{23,24}$ we hypothesized that the elevated IL-2 levels observed in treated mice could result in this promotion of Treg proliferation. Therefore, we examined the signaling of the STAT5 pathway, which is phosphorylated in response to IL-2, in Treg $\left(\mathrm{CD} 4^{+} \mathrm{CD} 25^{+} \mathrm{FOXP3} 3^{+}\right)$ but also in Tconv (CD4 ${ }^{+} \mathrm{FOXP3}^{-} \mathrm{T}$ cells) and $\mathrm{CD} 8^{+} \mathrm{T}$ cells. The levels of phosphorylated STAT5 (pSTAT5) were higher in Tconv, CD8 ${ }^{+} \mathrm{T}$ cells and Treg (and to a higher extent in the latter) from RAPA than from control mice (Figure 3C,D). Importantly, RAPA also increased the expression of CD25 (the high affinity component of the IL-2 receptor) in all T cell populations, thereby increasing their affinity for IL-2 and the capacity of IL-2 to induce STAT5 activation (Figure 3E).

In addition to IL-2, IL-7, and IL-15 are the other major inducers of STAT5 activation. ${ }^{25}$ Because mouse IL-7 can cross-react with human T cells, ${ }^{26}$ we assessed whether the serum collected from nontransplanted 


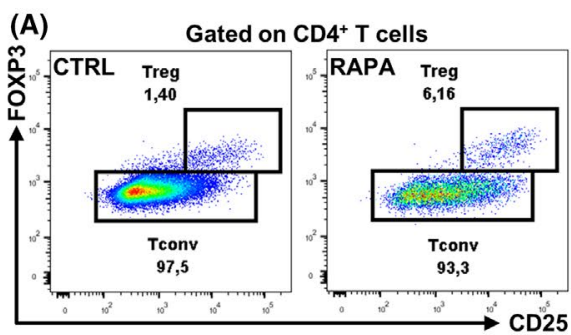

(C)

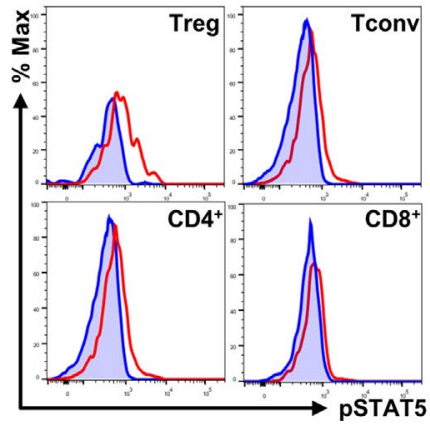

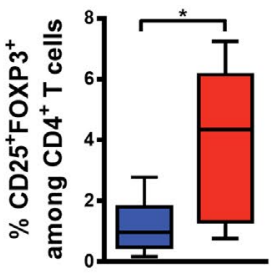

CD25

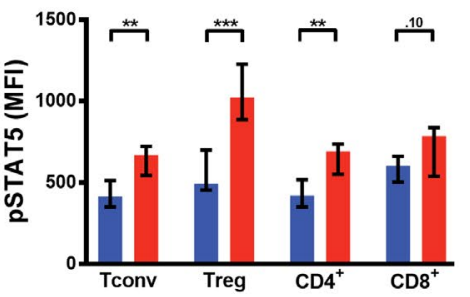

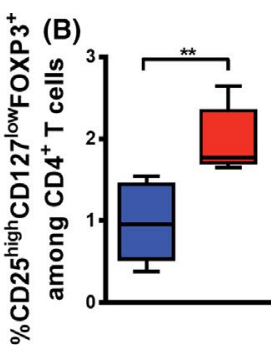

(D)

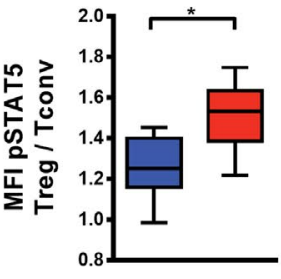

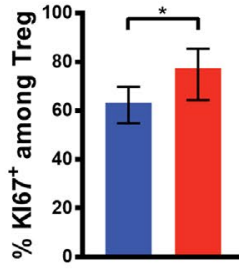

CTRL RAPA

(E)

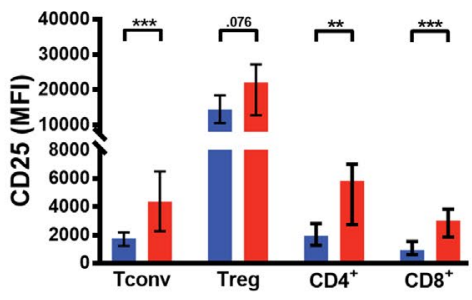

FIG URE 3 RAPA promotes regulatory T cells. NSG mice were transplanted with $2 \times 10^{6}$ human PBMCs, $24 \mathrm{~h}$ after $2.5 \mathrm{~Gy}$ TBI. Mice were then treated every $24 \mathrm{~h}$ with $1 \mathrm{mg} / \mathrm{kg}$ of RAPA on days +1 to +21 and were sacrificed at day 25 for flow cytometry analyzes of their spleen. (A) Representative FACS data (left panel) and comparison (right panel) of Treg frequencies. (B) Comparison of KI67 expression by Treg. (C) Representative FACS data (left panel) and comparison of phosphorylated-STAT5 (pSTAT5) mean fluorescence intensities (MFI) in indicated T cell populations. (D) Comparison of ratio, for each mouse treated or not with RAPA, of pSTAT5 MFI of Treg vs. pSTAT5 MFI of Tconv, based on MFI's found in C. (E) Comparison of CD25 MFI in indicated T cell populations. Data show median values with either interquartile range (B, $\mathrm{C}$, and $\mathrm{E}$ ) or 5-95 percentile (A and D) of 8-13 mice/condition $\left({ }^{*} p \leq .05,{ }^{* *} p<.01,{ }^{* * *} p<.001,{ }^{* * * *} p<.0001\right)$

NSG mice was able to induce STAT5 phosphorylation in human T cells. No increase of STAT5 phosphorylation was observed after 15 min incubation of human PBMCs in serum (concentrated or not) of NSG mice (Figure S5). Furthermore, no detectable human IL-15 was found in the serum of transplanted NSG mice by Bioplex, neither in control nor in RAPA group, at day 25 (data not shown). Altogether, these results show that RAPA promotes Treg proliferation through the signaling of STAT5, supported by increased IL-2 levels and CD25 expression.

\subsection{Interplay between RAPA and IL-2 in Treg and $\mathrm{CD}^{+} \mathrm{T}$ cell regulation}

To further investigate the link between RAPA and IL-2 signaling, we examined RAPA impacts on human T cells in vitro. To prevent rapamycin resistance subsequent to strong TCR signaling, ${ }^{27}$ the proliferation of $T$ cells was stimulated with a low amount of CD3/CD28 beads (1:20 bead:cell ratio) and cells were cultured for 12 days in presence or absence of RAPA. RAPA dramatically decreased T cell activation and proinflammatory cytokine secretion (Figure $4 A, B$ ). In contrast, IL-2 levels were only reduced by RAPA at day 4 while they were higher at day 12 (Figure 4C). FACS analyses made every $48 \mathrm{~h}$ from day 4 to 12 showed that the frequency of IL-2 ${ }^{+} \mathrm{T}$ cells gradually decreased in CTRL wells from day 4 to 12 while it remained stable in RAPA wells after day 6, leading to higher frequencies in RAPA vs CTRL after day 8 (Figure 4D). As this pattern was not different between $\mathrm{CD}^{+}$and $\mathrm{CD} 8^{+}$cells (Figure S6A), we hypothesized that this inversion could result from the differentiation of T cells. Accordingly, we found that the less differentiated $\left(C D 27^{+}\right)$memory (CD45RA $\left.{ }^{-}\right) \mathrm{T}$ cells secreted much less IL-2 than their more differentiated (CD27') counterparts (Figure 4E; Figure S6B) and that the pattern of IL-2 secretion followed closely the pattern of CD45RA ${ }^{-} C D 27^{+} \mathrm{T}$ cells frequency (Figure 4F). Therefore, we conclude that the higher IL-2 levels observed at later time points result from the global reduction of $\mathrm{T}$ cell differentiation mediated by RAPA (Figure 4G).

In concordance with the observed IL-2 levels, the levels of pSTAT5 and CD25 were respectively reduced and increased by RAPA at days 4 and 12, in line with our findings in mice (Figure 4H,I). The importance of the interplay between RAPA and IL-2 in Treg promotion was supported by the frequency of Treg which was decreased and increased by RAPA at days 4 and 12, respectively (Figure $4 \mathrm{~J}$ ). Importantly, inhibition of IL-2 signaling through anti-IL-2 and anti-CD25 blocking antibodies resulted in pSTAT5 levels similar to unstimulated T cells, showing that IL-2 was the sole cytokine involved in STAT5 phosphorylation in this system (Figure S6C). Further, in these conditions of IL-2 inhibition, no promotion of Treg frequency by RAPA could be observed (Figure 4K). Finally, RAPA had no direct effect on STAT5 phosphorylation as pre-incubation of T cells with RAPA before measuring pSTAT5 levels in response to IL-2 yielded identical response curves in treated and control T cells (Figure 4L). Altogether, these data show that RAPA impact on Treg is mediated in large part through its effects on IL-2 levels and subsequent STAT5 signaling. 


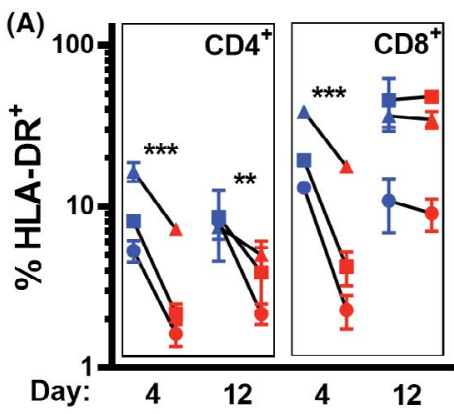

(B) 으
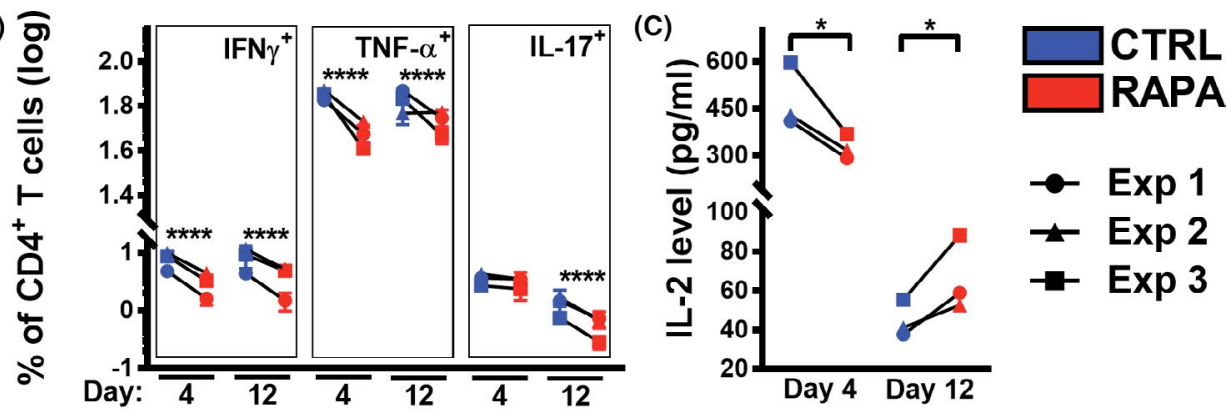

(D)

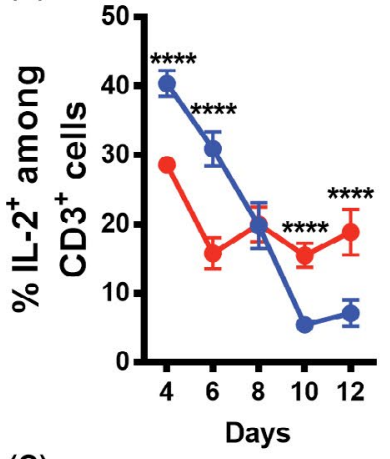

(G)

(E)

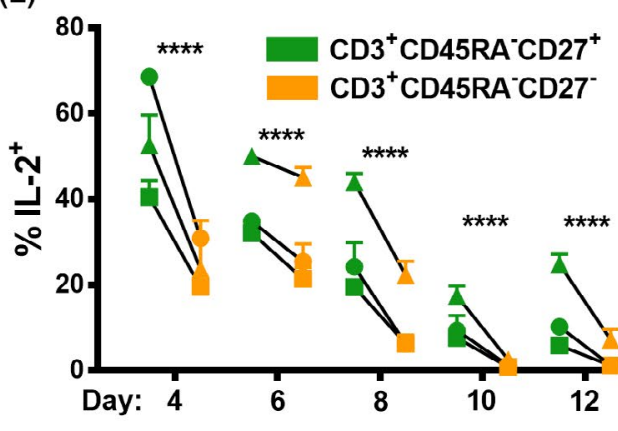

(F)

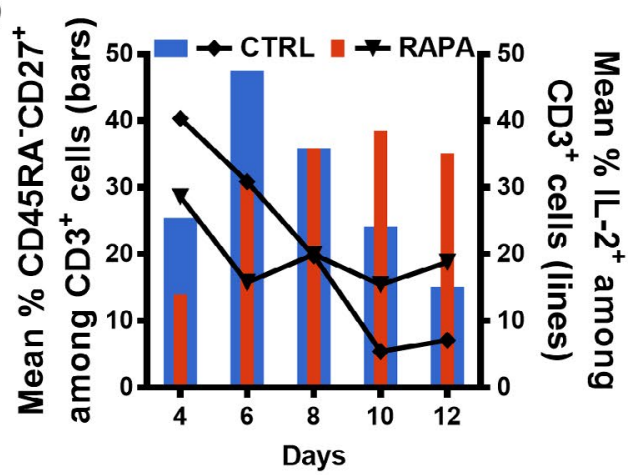

(H)

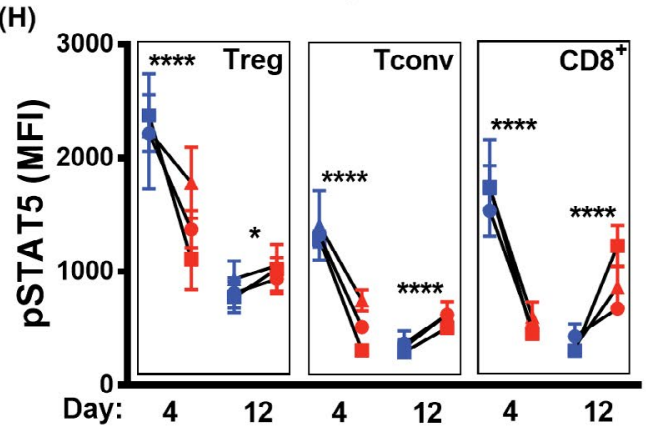

(K)
(I)

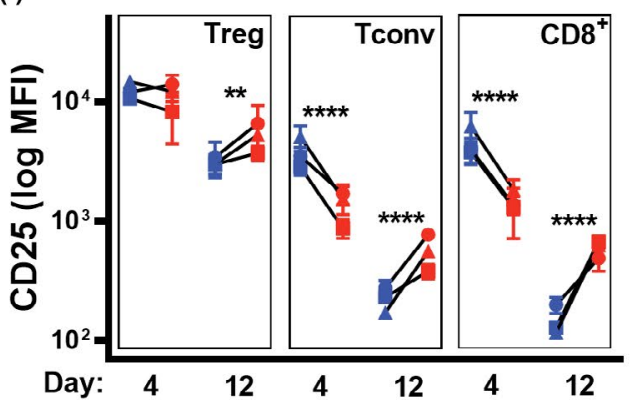

(J)

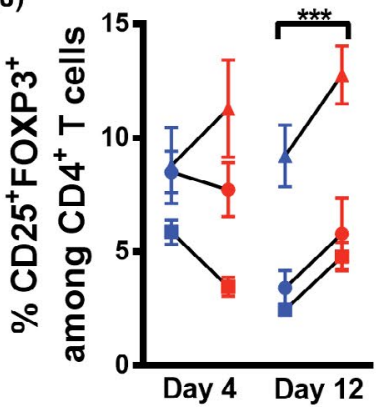

(L)

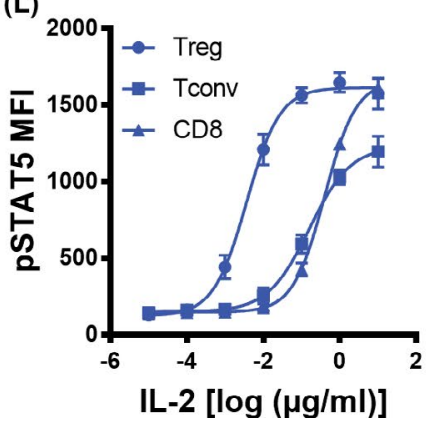

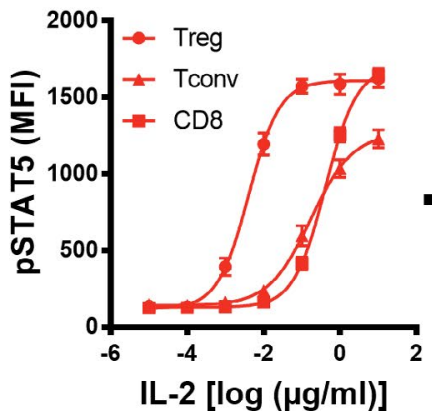
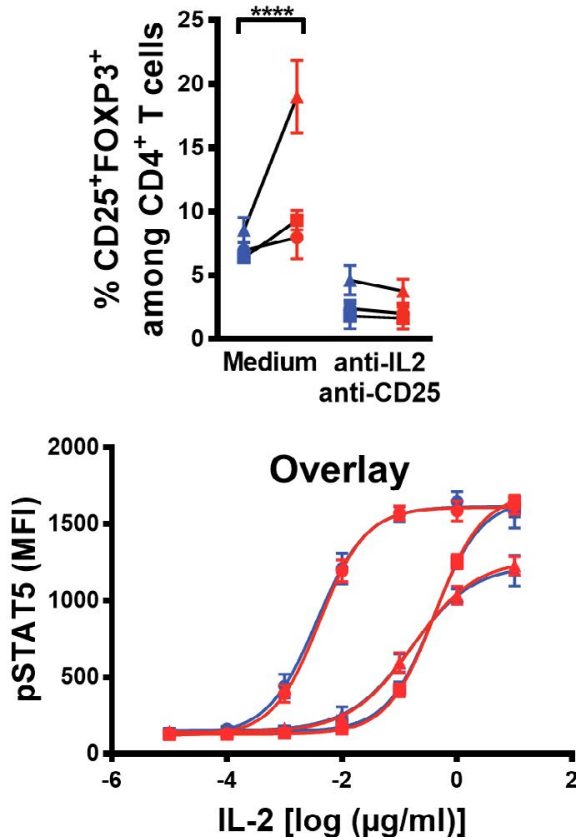
FIGURE 4 Ex-vivo effects of RAPA on T cells. Human T cells were freshly isolated from three different healthy volunteers (three experiments each performed in triplicates, $n=9 /$ condition) and were stimulated with CD3/CD28 beads (bead-cell ratio: 1-20), in presence or not of $100 \mathrm{nmol} / \mathrm{L}$ of RAPA (A-J) or were used immediately for STAT5 phosphorylation assays (L). Flow cytometry analyzes of RAPA effects in stimulated cultures were performed at days 4 and 12 (A,B, H-J), from day 4 to 12 (D-G) or at day 7 (K). (A) Frequency of HLA-DR in indicated T cell populations. (B) Frequency of indicated cytokines in CD4 ${ }^{+} \mathrm{T}$ cells. (C) Bioplex assay of IL-2 concentration in the medium of one replicate from each experiment ( $n=3$ /condition). (D) Frequency of IL-2 ${ }^{+}$among $C D 3^{+}$cells. (E) Frequency of IL-2 ${ }^{+}$cells among CD45RA ${ }^{-}$CD $27^{+}$and CD45RA ${ }^{-}$CD27 $7^{-}$cells in CTRL condition. (F) Frequency of IL-2 ${ }^{+}$(lines) and CD45RA ${ }^{-}$CD27 $7^{+}$(bars) T cells. (G) Mean frequency of indicated populations among $T$ cells, stars indicate statistically significant comparisons with respective controls. $(\mathrm{H}) \mathrm{Mean}$ fluorescence intensity (MFI) of STAT5 phosphorylation level (pSTAT5) in indicated T cell populations. (I) Mean fluorescence intensity of CD25 in indicated T cell populations. (J) Frequency of Treg. (K) Frequency of Treg in normal conditions (Complete medium $+C D 3 / C D 28$ stimulation) and upon inhibition of IL-2 signaling (Complete medium +CD3/CD28 stimulation +anti-IL-2 blocking antibodies +anti-CD25 blocking antibodies). (L) Phosphorylation of STAT5 in response to various concentrations of IL-2 in unstimulated, freshly isolated T cells, preincubated or not for $4 \mathrm{~h}$ with $1 \mathrm{\mu mol} / \mathrm{L}$ of RAPA. Data show mean values with standard deviations $\left({ }^{*} p \leq .05,{ }^{* *} p<.01,{ }^{* * *} p<.001,{ }^{* * * *} p<.0001\right)$

Next, we asked whether this impact of RAPA on IL-2 signaling could be implicated in its modulation of the CD4/CD8 ratio, given the dependence of $\mathrm{CD} 8^{+} \mathrm{T}$ cells upon IL- $2 .{ }^{28}$ In our cell culture system, this dependence was well observed as (i) culture of $\mathrm{T}$ cells in presence of either 0 or $100 \mathrm{ng} / \mathrm{ml}$ of IL- 2 or $1 \mathrm{ng} / \mathrm{ml}$ of IL-7 alone resulted in a gradual decrease of the CD4/CD8 ratio, (ii) their culture in presence of IL-7 with blockade of IL-2 signaling through anti-IL-2 and anti-CD25 neutralizing antibodies resulted in a relatively stable ratio over time and (iii) the decrease of IL-2 availability through supplementation of anti-IL-2 neutralizing antibodies (which do not hamper IL-2 capture by $\mathrm{CD} 25^{\text {high }} \mathrm{T}$ cells) tended to increase the CD4/CD8 ratio (Figure 5A). As observed in mice, RAPA increased the $C D 4 / C D 8$ ratio in the course of the culture, independently of the presence of Treg (Figure 5B). Critically, supplementation of IL-2 in the growth medium resulted in a decrease of RAPA effect on CD4/CD8 ratios while supplementation of IL-7 had no impact on RAPA effects (Figure $5 C-E$ ). However, the CD4/CD8 ratio was unaffected by RAPA when $T$ cells were cultured in presence of IL-7 and with blockade of IL-2 (Figure 5F). Altogether, these data demonstrate that the interplay between RAPA and IL-2 signaling plays a critical role in its regulation of Treg and cytotoxic T cells.

\section{6 | Impact of postgrafting RAPA treatment in patients after nonmyeloablative allo-HCT}

Next, we assessed whether the imprint of RAPA treatment on T cells observed in mice and cell cultures could also be observed in patients treated with tacrolimus (TAC) plus mycophenolate mofetil (MMF) ( $n=18$ ) or TAC plus RAPA $(n=20)$ as GVHD prophylaxis after nonmyeloablative allo-HCT conditioning (fludarabine $90 \mathrm{mg} / \mathrm{m}^{2}+2 \mathrm{~Gy}$ TBI) (Table S1).

As shown in Figure 6A, RAPA-treated patients had increased CD4/CD8 ratios at all time points and lower total number of $\mathrm{CD}^{+} \mathrm{T}$ cells per $\mu$ of blood, while numbers of $C D 4^{+} T$ cells were unaffected (Figure S7), supporting a greater anti-proliferative impact of RAPA on $\mathrm{CD}^{+}$than on $\mathrm{CD} 4^{+} \mathrm{T}$ cells. Higher levels of $\mathrm{BCL}-2$ expression were observed in both T cell populations of RAPA-treated patients, suggesting that RAPA also promoted resistance to apoptosis in these conditions (Figure S8).
In line with observations in mice, RAPA decreased the frequency of effector memory (TEM) and effector memory re-expressing CD45RA (TEMRA) while increased the frequency of naive (TN) $\mathrm{CD}^{+}$and $\mathrm{CD}^{+} \mathrm{T}$ cells (Figure 6B; Figure S9). The higher frequencies of naive $T$ cells observed in the RAPA group could not be attributed to a higher thymic production as the frequencies of $\mathrm{CD} 4^{+} \mathrm{CD} 45 \mathrm{RA}^{+} \mathrm{CD} 31^{+}$recent thymic emigrants were mostly unaffected by RAPA (Figure S10). Lowered expression of HLA-DR and Granzyme-B in treated patients were also observed (Figure 6C,D; Figure S11). The secretion of IFN- $\gamma$ by $C D 4^{+} T$ cells tended to be decreased at days 100,180, and 365, while the secretion of IL-2 was increased, in RAPA patients (Figure 6E,F).

As expected, RAPA increased Treg frequencies and numbers (Figure 6G; Figure S12). The KI67 expression of CD4 ${ }^{+}$conventional T cells was reduced by RAPA while KI67 expression by Treg was unchanged, providing them with a proliferative advantage over Tconv (Figure 6H; Figure S13). In line with the higher IL-2 secretion in TAC+RAPA patients, RAPA tended to increase the phosphorylation of STAT5 in Treg, while it remained mostly unchanged in Tconv, at the three first time points (Figure 6I; Figure S14). Finally, higher CD25 expression was observed in all examined populations (Figure 6J; Figure S15). Altogether, these data support our observations made in mice and cell cultures and provide an integrative analysis of RAPA effects on human T cells in the transplantation setting.

\subsection{Combination of RAPA with other immunosuppressive drugs}

Based on our findings showing that RAPA effects on T cells depend on IL-2-CD25-STAT5 signaling, we hypothesized that combining RAPA with drugs antagonizing IL-2 would mitigate RAPA beneficial effects. We therefore treated NSG mice with RAPA and/or TAC and found that the combination delayed GVHD (while this was not significant when compared to RAPA alone, Figure S16A). However, the extremely low engraftment in RAPA+TAC mice (median $=2.73 \%$ at day 21) prevented us from analyzing the drug combination effects on T cells. As we showed here that human T cell proliferation in NSG mice is solely dependent on IL-2, we hypothesized that the full inhibition of $\mathrm{T}$ cell expansion (which probably resulted in the better 
(A)

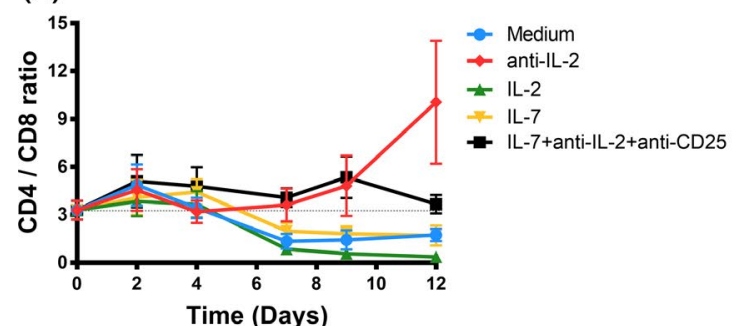

(C)

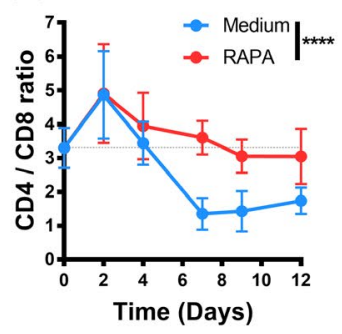

(D)

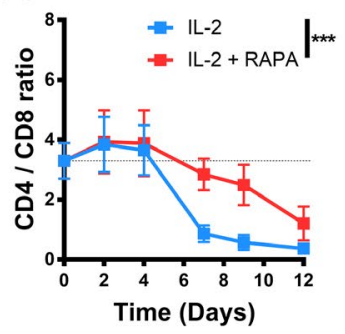

(B)

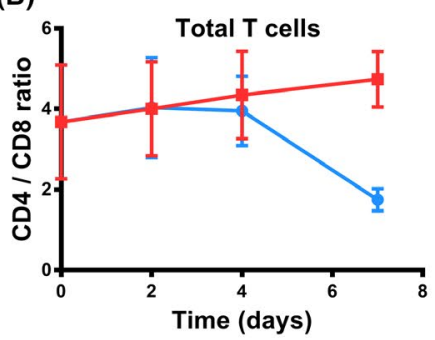

(E)

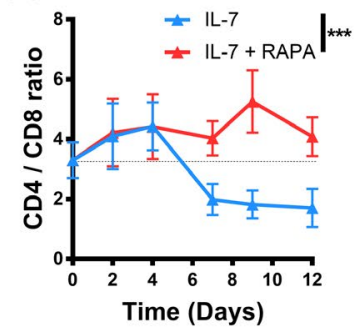

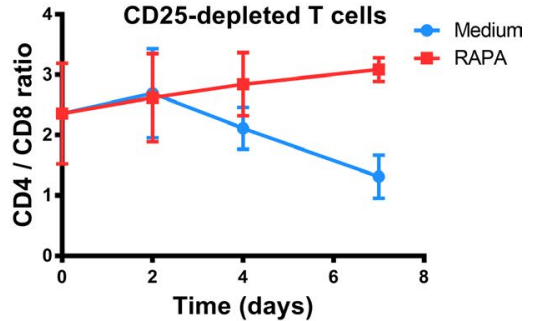

(F)

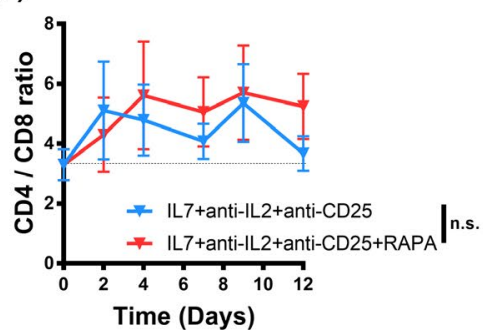

FIGURE 5 Impact of RAPA and IL-2 on CD4/CD8 ratio. (A, C-F) Human T cells were freshly isolated from three different healthy volunteers (three experiments each performed in triplicates, $n=9 /$ condition) and were stimulated with CD3/CD28 beads (bead-cell ratio: 1-20), in presence or not of $100 \mathrm{nmol} / \mathrm{L}$ of RAPA, and were supplemented with either IL-2, IL-7, anti-IL-2 blocking antibodies or anti-IL-2 blocking antibodies +anti-CD25 blocking antibodies +IL-7. Flow cytometry analyzes of CD4/CD8 ratio were performed after $48 \mathrm{~h}$ (day 2 ), $96 \mathrm{~h}$ (day 4), $168 \mathrm{~h}$ (day 7), $216 \mathrm{~h}$ (day 9), and $288 \mathrm{~h}$ (day 12) after the beginning of culture. (B) Human T cells, freshly isolated from three different healthy volunteers (three experiments each performed in triplicates, $n=9 /$ condition), were depleted of $C D 25^{+} T$ cells and were stimulated with CD3/CD28 beads (bead-cell ratio: 1-20), in presence of $100 \mathrm{nmol} / \mathrm{L}$ of RAPA or not. Flow cytometry analyzes of CD4/CD8 ratio were performed after $48 \mathrm{~h}$ (day 2), $96 \mathrm{~h}$ (day 4), and $168 \mathrm{~h}$ (day 7) after the beginning of culture. Data show mean values with standard deviations $\left({ }^{*} p \leq .05,{ }^{* *} p<.01,{ }^{* * *} p<.001,{ }^{* * * *} p<.0001\right)$

survival) by TAC+RAPA could be attributed to the absence of IL-7, that could support $T$ cell expansion in absence of IL-2 signaling, in NSG mice. We therefore expanded in vitro T cells in presence of IL-7 and found that the RAPA+TAC combination dramatically reduced IL-2 secretion, CD25 expression, STAT5 phosphorylation and Treg expansion compared to RAPA alone (Figure S16B), thereby confirming the mitigation of RAPA beneficial effects by CNIs.

Next, we reasoned that combining RAPA with another drug also promoting IL-2 signaling, such as 5 -azacytidine (AZA), ${ }^{18}$ could result in a possible synergy. We performed this experiment in NSG-HLA-A2/ HHD mice (which express HLA-A2 in addition to mouse MHC molecules) transplanted with human PBMCs, which develop a dual alloand xeno-GVHD. ${ }^{17}$ The combination delayed the onset and severity of GVHD, compared to control or RAPA alone (Figure S17A,B) but no striking difference was observed vs AZA only. Synergistic effects on $T$ cell engraftment and CD4/CD8 balance were found (Figure S17C,D). The combination also induced higher Treg proliferation, despite no significant increase of their frequency was observed (Figure S17E,F). However, while pSTAT5 levels were increased in Treg in all treated arms compared to untreated mice, the highest levels of Treg-pSTAT5/ Tconv-pSTAT5 ratio tended to be observed in the combination arm (Figure S17G-I). Finally, the highest levels of naive CD4 ${ }^{+}$cells were observed in the combination arm (Figure S17J).

Because no benefits on survival were observed with the RAPA+AZA combination (vs. AZA only), we tested whether RAPA could have synergistic effects on survival with posttransplant cyclophosphamide (PTCy), another Treg-promoting drug increasingly investigated and used in GVHD prophylaxis. ${ }^{29}$ PTCy significantly ameliorated GVHD survival and severity and the combination improved these parameters in comparison to RAPA alone (Figure S18A,B). Interestingly, there was a suggestion toward a better median survival with the drug combination compared to PTCy alone (76 vs 64 days, $p=$ n.s.). However, at the immunological level no synergy could be observed except on the CD4/CD8 ratio (Figure S18C,D).

FIGURE 6 Effects of postgrafting immunosuppression with RAPA. Cryopreserved PBMCs, prospectively collected during a randomized phase II clinical trial (details of the trial can be found in the supplemental data and on clinicaltrials.gov \#NCT01428973) assessing the efficacy of RAPA in combination with Tacrolimus vs Mycophenolate Mofetil (MMF) in combination with Tacrolimus, were immunophenotyped by flow cytometry to assess the in vivo effects of RAPA on human T cells in physiologically relevant conditions. Data were obtained from samples collected in 18 patients included in the MMF arm and 20 in the RAPA arm. (A) Comparison of the CD4/CD8 ratio at days 40,100,180, and 365 after the beginning of RAPA or MMF administration. (B) Frequencies of effector memory re-expressing CD45RA (TEMRA, CD45RA ${ }^{+}$CD62 $L^{-}$), effector memory (TEM, CD45RA ${ }^{-}$CD62 $L^{-}$), central memory (TCM, CD45RA ${ }^{-} \mathrm{CD} 6 \mathrm{~L}^{+}$), stem-cell

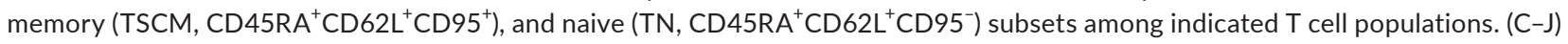
Indicated frequencies and mean fluorescence intensities (MFI) were measured in indicated populations at days 40, 100, 180, and 365 after the beginning of RAPA or MMF administration. Data show the median, 25th and 75th percentiles of the distribution (boxes), and whiskers extend to the 5th and 95th percentiles. The $p$-value of ANOVA-2 statistical tests comparing the effect of treatment on variation of data are reported on each panel $\left({ }^{*} p \leq .05,{ }^{* *} p<.01,{ }^{* * *} p<.001,{ }^{* * * *} p<.0001\right)$ 
(A)
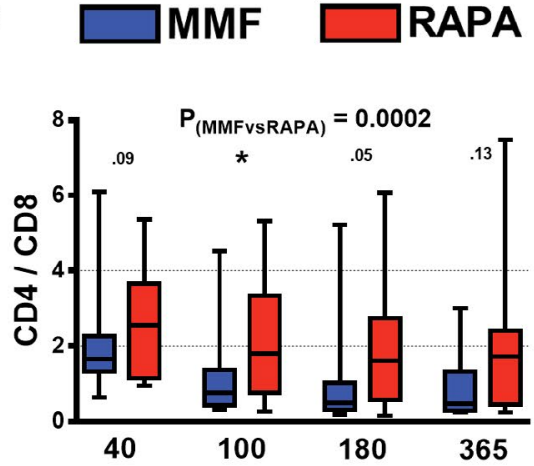

(C)

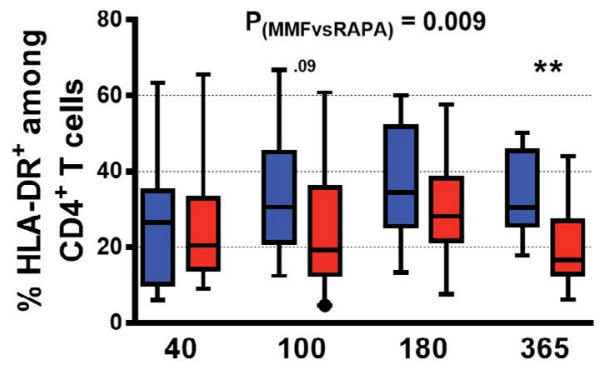

(D)

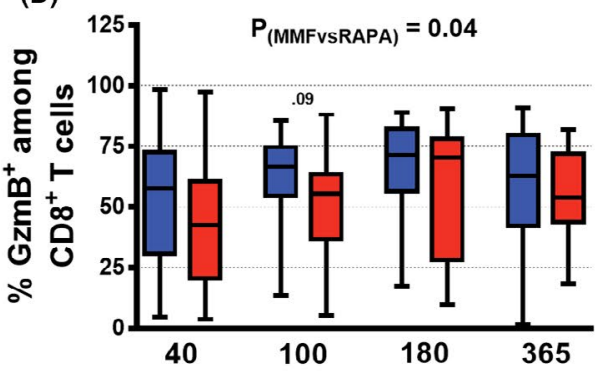

(E)

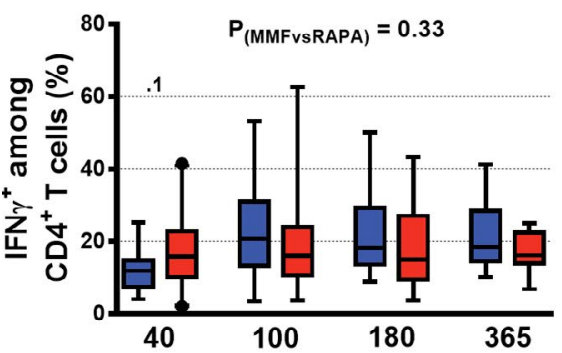

(H)

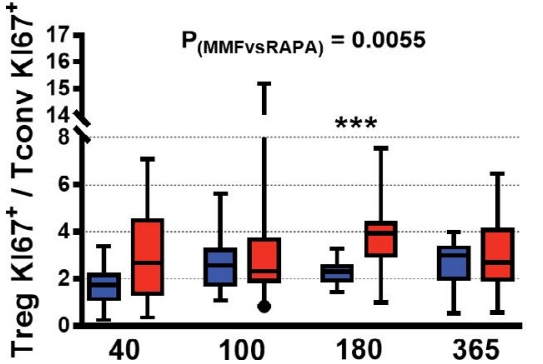

(B)

40

100

180

365

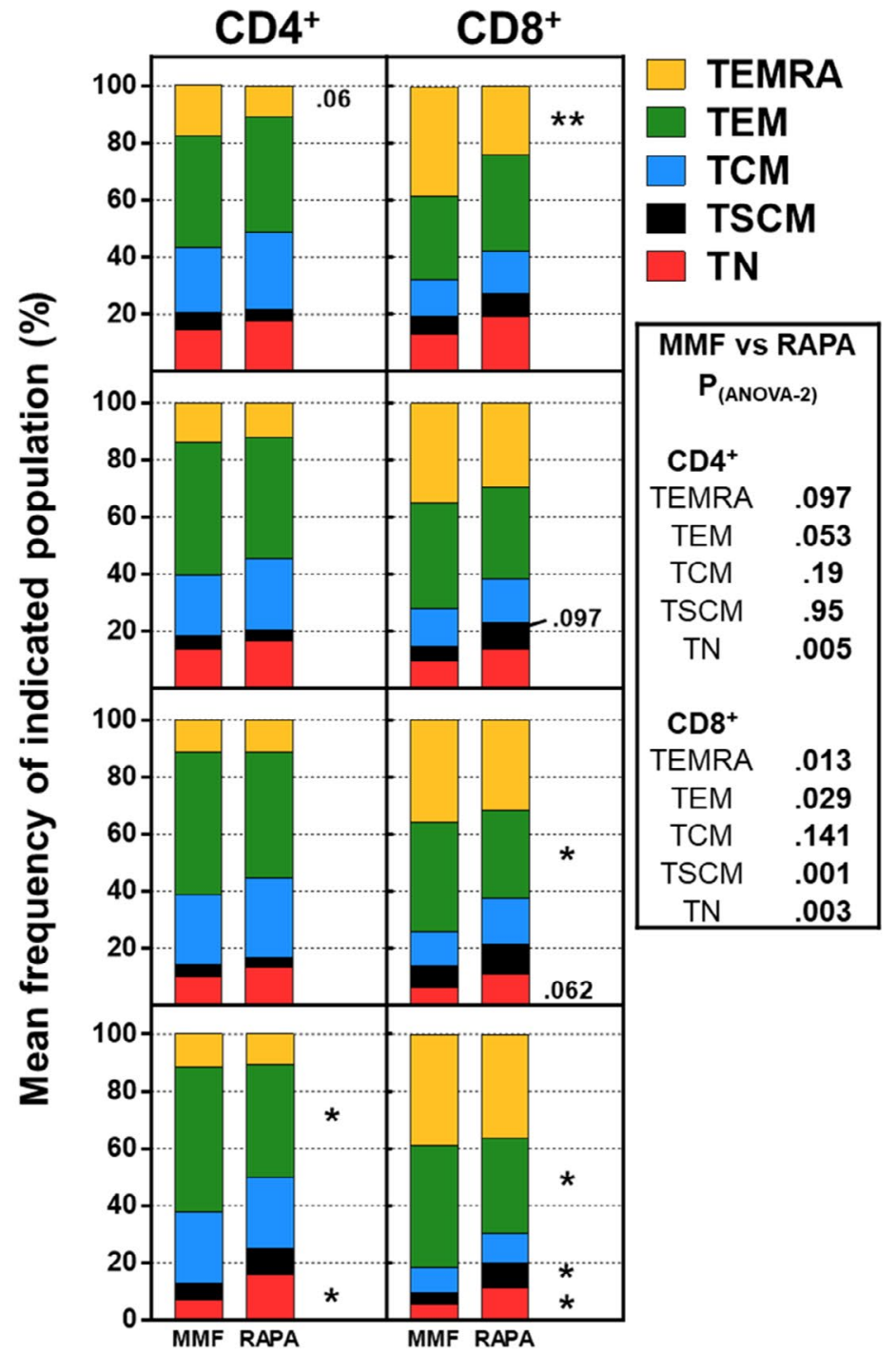

(G)

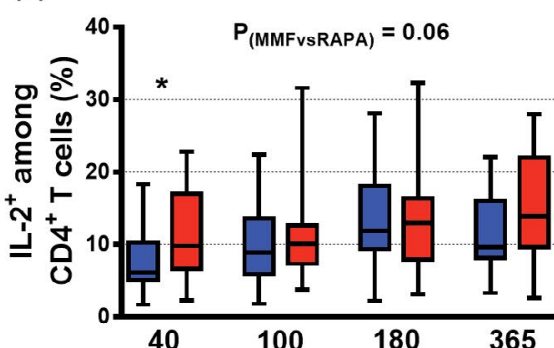

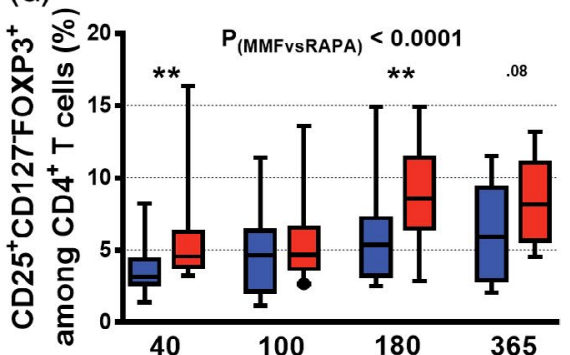

(I)

(J)

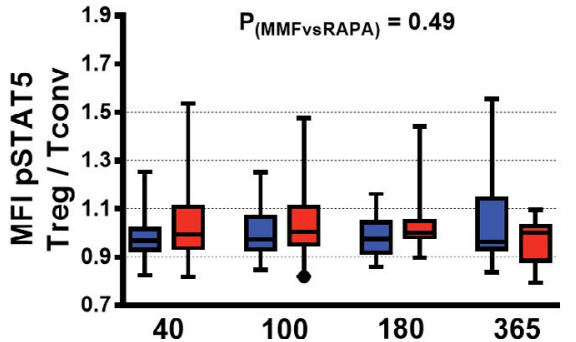

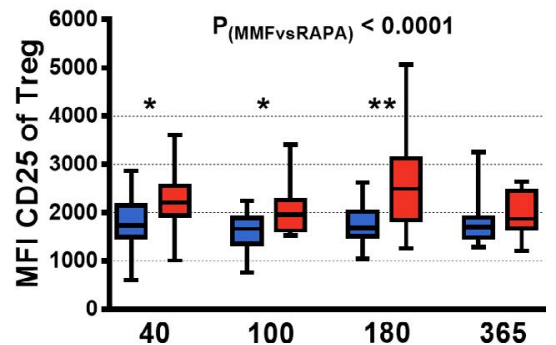




\section{DISCUSSION}

Several trials assessing RAPA for GVHD prophylaxis, usually combined with $\mathrm{CNIs}$ have yielded conflicting results regarding its impact on survival. These contrasted results could result from a lack of knowledge about the immunological-related mechanisms of action of RAPA on human cells. Here, we report a comprehensive analysis of the in vivo immunomodulatory effects of RAPA on human T cells in allo-HCT and GVHD. Our results may help overcoming the obstacles to the routine use of RAPA as GVHD prophylaxis.

Following activation, $T$ cells differentiate in a stepwise process from TN to TSCM, TCM and finally to TEM/TEFF/TEMRA which are characterized by the strongest pro-inflammatory and cytotoxic properties. ${ }^{30}$ Here, RAPA increased the frequencies of TN, TSCM and TCM over the other subsets. As RAPA decreased T cell activation and proliferation, the higher frequencies of less differentiated subsets are most likely the result of a decreased differentiation rather than of the overgrowth of less- over more-differentiated subsets. Accordingly, RAPA decreased the expression of pro-inflammatory and cytotoxic molecules. In allo-HCT recipients, higher frequencies of more differentiated $\mathrm{T}$ cell subsets are associated with higher risks of GVHD development. ${ }^{31-33}$ Therefore, this effect of RAPA could have a pivotal role in the prevention of GVHD.

In contrast, other reports have suggested that less differentiated $T$ cell subsets could be the main mediators of GVHD as they retain their functional and proliferative potential. ${ }^{34,35}$ Here, upon secondary transplantation, RAPA-treated T cells induced severe GVHD while untreated $T$ cells failed to expand in secondary recipients, possibly subsequently to high senescence. This observation is in line with data suggesting that less differentiated T cells can lead to more severe GVHD but it also suggests that an antigenic re-stimulation (the secondary transplantation here) is required after RAPA treatment to trigger the effector response of T cells. Consequently, this effect could play a pivotal role in preventing relapse after allo-HCT for hematological malignancies where RAPA could promote the long-term survival of $T$ cells retaining their anti-tumor potential.

We showed that RAPA increased the expression of BCL-2 by both $\mathrm{CD}^{+}$and $\mathrm{CD}^{+}{ }^{+}$cell populations, in line with previous findings. ${ }^{36}$ In agreement with the anti-apoptotic function of BCL-2, a reduced frequency of apoptotic T cells was observed in RAPA-treated animals. Interestingly, a previous report demonstrated that the induction of resistance to RAPA through long-term exposure of T cells to the drug conferred a high resistance to apoptosis (characterized by a high expression of $\mathrm{BCL}-2$ ) and a high proliferative capacity upon injection in NSG mice. ${ }^{37}$ Therefore, this high resistance to apoptosis could be involved in the high engraftment capacity of human $\mathrm{CD} 45^{+}$cells isolated from the spleen of RAPA-treated mice in secondary transplantations. Further, these data also indicate that RAPA-resistant $T$ cells, which are under investigation for their possibly greater anti-tumor activities, ${ }^{38}$ could lead to exacerbation of GVHD in recipients of allo-HCT.

RAPA also reduced $C D 8^{+}$vs. $C D 4^{+} T$ cell frequency. While a differential inhibitory effect of RAPA on the activation of $\mathrm{CD}^{+}$and
$\mathrm{CD}^{+} \mathrm{T}$ cells cannot be ruled out, our in vitro experiments indicate that RAPA represses $\mathrm{CD}^{+} \mathrm{T}$ cells through a greater inhibition of their cytokine-supported proliferation, as the CD4/CD8 ratio is not altered by RAPA upon IL-7-driven proliferation and is modulated by the availability of IL-2. Interestingly, another team showed that RAPA inhibits $\mathrm{CD}^{+} \mathrm{T}$ cell proliferation by preventing the downregulation of the cell-cycle regulator $\mathrm{p} 27^{\mathrm{kip} 1}$ following $\mathrm{T}$ cell activation, ${ }^{39}$ dependently of the strength of TCR stimulation. ${ }^{27}$ We show that IL-2 availability is also a key player in this inhibition. Notably, (i) p2 $27^{\text {kip1 }}$ regulation of cell cycle is tightly modulated by IL-2, ${ }^{40}$ (ii) RAPA is capable of mediating cell cycle arrest through $\mathrm{p} 27^{\mathrm{kip} 1}$ upregulation, ${ }^{41}$ (iii) IL-2 stimulates proliferation through $\mathrm{p} 27^{\mathrm{kip} 1}$ downregulation in $\mathrm{CD}^{+}$, but not in $\mathrm{CD}^{+}$, $\mathrm{T}$ cells, ${ }^{42}$ and (iv) IL-7 promotes proliferation by downregulating $\mathrm{p} 27^{\mathrm{kip} 1}$ in both $\mathrm{CD} 4^{+}$and $\mathrm{CD} 8^{+} \mathrm{T}$ cells. ${ }^{43}$ Altogether, these data suggest that RAPA effects on $\mathrm{p} 27^{\mathrm{kip} 1}$ could be the key to explain its selective and cytokine-dependent modulation of $\mathrm{CD}^{+} \mathrm{T}$ cells. While future investigations will be necessary to verify this hypothesis, our data demonstrate that the effects of RAPA in allo-HCT are influenced by the cytokine milieu and therefore could be altered by the extent of lymphopenia (more or less homeostatic cytokines such as IL-7) and inflammation (more or less IL-2 or other cytokines with similar effects).

Despite the deleterious effects of RAPA on $\mathrm{CD} 8^{+} \mathrm{T}$ cells and on $T$ cell differentiation, we could not highlight any deleterious impact on GvL effects, in contrast with previous reports in mouse-to-mouse transplantation models. ${ }^{44,45}$ As AML cells escape from the GvL effect results in part from a promotion of CD8 T cell exhaustion, ${ }^{46}$ we hypothesize that the maintenance of the GvL effect in RAPA treated mice could result from the preserved effector and proliferative capacity of RAPA-treated T cells observed in our secondary transplant experiments. Further, although not present in our GvL model (THP-1 cells are RAPA resistant), RAPA can mediate direct anti-tumor effects through mTOR inhibition in selected tumors. ${ }^{47,48}$

We found that RAPA conducted to higher STAT5 signaling, subsequent to higher IL-2 levels, which resulted in the promotion of Treg proliferation. In vivo, these higher levels of IL-2 could be attributed to increased secretion of IL-2 by T cells. Our in vitro experiments demonstrated that RAPA promotes IL-2 secretion through the reduction of $\mathrm{T}$ cell differentiation as lessdifferentiated memory $T$ cells produce significantly more IL-2 than their effector counterparts. Importantly, RAPA recurrently induced a robust overexpression of CD25, which can also participate to the higher IL-2-STAT5 signaling as STAT5 phosphorylation levels strongly depend on CD25 expression. ${ }^{49}$ While this increased CD25 expression could result directly from the higher availability of IL-2, ${ }^{50}$ it could also result from a positive selection of CD25 ${ }^{+}$over $\mathrm{CD} 25^{-}$cells by RAPA. ${ }^{51}$ Altogether, these data show that RAPA-promoting effects on Treg depend at least in part on the IL-2-CD25-STAT5 axis.

There are some limitations in our study. While xGVHD in NSG mice previously yielded results concordant with GVHD physiopathology, ${ }^{17,18}$ the absence of IL-7 and IL-15 in this model, highlighted herein, could have altered the relevance of some of our conclusions. 
Furthermore, as RAPA has been reported to impact T cells, and especially Tregs, through its effects on endothelial cells, ${ }^{52}$ some of our observations could result in part from endothelial cells-dependent mechanisms. However, the concordances of the observations made in mice versus in patients (for the cytokine bias) and in mice versus in vitro (for the endothelial cells bias) suggest that the extent of these possible biases is limited. In addition, the design of the prospective trial (randomization between TAC+MMF vs. TAC+RAPA) underestimate the anti-GVHD potential of RAPA since MMF is no given in the TAC+RAPA arm. In line with this hypothesis, a recent important phase III trial demonstrated that addition of RAPA to standard cyclosporine+MMF GVHD prophylaxis in patients given grafts from HLAmatched unrelated donors after nonmyeloablative conditioning reduced the incidence of acute GVHD and improved progressionfree survival. ${ }^{53}$

Our findings might shed new light on results of clinical trials previously published and help to design future studies of RAPA in GVHD prophylaxis. Specifically, we demonstrated that RAPA effects on Tregs and CD8 ${ }^{+} T$ cells depend on IL-2 signaling. Therefore, the use of CNI (which reduce IL-2 levels) in combination with RAPA might restrain its therapeutic potential. Importantly, all our patients treated with RAPA also received TAC, which could explain the relatively low amplitude of the effects on pSTAT5 in comparison with observations in mice and cultures. Further, as RAPA increased al $T$ cell CD25 expression (and therefore $T$ cell affinity for IL-2), the administration of low doses of IL-2 might lose in part its specificity for Treg promotion when used in combination with RAPA. RAPA might show better outcomes if used in combination with synergistic drugs such as 5 -azacytidine ${ }^{18,54}$ or anti-CD45RC antibodies. ${ }^{55}$ Indeed, our pilot experiments highlighted encouraging synergistic effects between AZA and RAPA, paving the way to future consideration of this combination for further experimental validation and possibly clinical evaluation. Nevertheless, we assume that the relative low amplitude of the synergistic effects observed herein could result from exaggerated immunosuppression in mice receiving the treatment combinations, as we did not combine sub-optimal doses of each drugs.

\section{ACKNOWLEDGMENTS}

We are grateful to Sandra Ormenese and Raafat Stephan from the Imaging and Flow Cytometry Platform of the GIGA for help with flow cytometry analyses. This study was supported by funds from: the National Fund for Scientific Research (FNRS) (grant numbers T.0069.15 and T.0016.20), the Belgian Fondation contre le cancer (grant \# FBC \# FAF-C/2016/889), and the Leon Fredericq Fund and Anti-Cancer Center at the University of Liège. GE, CR, and LD were/ are Télévie Research Assistants, and FB is a senior research associate of the National Fund for Scientific Research (FNRS) Belgium. SHB is funded by the Fonds Wetenschappelijk Onderzoek (FWO).

\section{DISCLOSURE}

The authors of this manuscript have no conflicts of interest to disclose as described by the American Journal of Transplantation.

\section{AUTHOR CONTRIBUTIONS}

$\mathrm{GE}, \mathrm{CR}, \mathrm{MH}, \mathrm{SD}$, and LD performed the experiments; GE, CR, MH, and $\mathrm{FB}$ analyzed and interpreted the data; EW, SS, PD, and YB helped in data interpretation; EW, SS, YB, and FB designed and performed the clinical study and samples collection; GE and FB designed the research; GE and FB wrote the article and all authors edited and approved the manuscript.

\section{DATA AVAILABILITY STATEMENT}

The datasets supporting the conclusions of this article are included within the article and its additional files. Raw files used and/or analyzed during the current study are available from the corresponding author on reasonable request.

\section{ORCID}

Grégory Ehx (D) https://orcid.org/0000-0002-7018-1770

\section{REFERENCES}

1. Baron F, Storb R. Allogeneic hematopoietic cell transplantation as treatment for hematological malignancies: a review. Springer Semin Immunopathol. 2004;26(1-2):71-94.

2. Zeiser R, Socie G, Blazar BR. Pathogenesis of acute graft-versushost disease: from intestinal microbiota alterations to donor $\mathrm{T}$ cell activation. Br J Haematol. 2016;175(2):191-207.

3. Storb R, Antin JH, Cutler C. Should methotrexate plus calcineurin inhibitors be considered standard of care for prophylaxis of acute graft-versus-host disease? Biol Blood Marrow Transplant. 2010;16(1 Suppl):S18-S27.

4. Bacigalupo A, Vitale V, Corvò R, et al. The combined effect of total body irradiation (TBI) and cyclosporin $\mathrm{A}(\mathrm{CYA})$ on the risk of relapse in patients with acute myeloid leukaemia undergoing allogeneic bone marrow transplantation. $\mathrm{Br} J$ Haematol. 2000;108(1):99-104.

5. Craddock $C$, Nagra S, Peniket A, et al. Factors predicting long-term survival after T-cell depleted reduced intensity allogeneic stem cell transplantation for acute myeloid leukemia. Haematologica. 2010;95(6):989-995.

6. Powell JD, Lerner CG, Schwartz RH. Inhibition of cell cycle progression by rapamycin induces $T$ cell clonal anergy even in the presence of costimulation. J Immunol. 1999;162(5):2775-2784.

7. Fantus D, Thomson AW. Evolving perspectives of mTOR complexes in immunity and transplantation. Am J Transplant. 2015;15(4):891-902.

8. Delgoffe GM, Pollizzi KN, Waickman AT, et al. The kinase mTOR regulates the differentiation of helper $T$ cells through the selective activation of signaling by mTORC1 and mTORC2. Nat Immunol. 2011;12(4):295-303.

9. Pollizzi $\mathrm{KN}$, Patel $\mathrm{CH}$, Sun I-H, et al. mTORC1 and mTORC2 selectively regulate $\mathrm{CD} 8(+) \mathrm{T}$ cell differentiation. J Clin Invest. 2015;125(5):2090-2108.

10. Zeiser R, Nguyen $\mathrm{VH}$, Beilhack A, et al. Inhibition of CD4+CD25+ regulatory $\mathrm{T}$-cell function by calcineurin-dependent interleukin-2 production. Blood. 2006;108(1):390-399.

11. Coenen JJA, Koenen H, van Rijssen E, et al. Rapamycin, not cyclosporine, permits thymic generation and peripheral preservation of CD4+ CD25+ FoxP3+ T cells. Bone Marrow Transplant. 2007;39(9):537-545.

12. Peccatori J, Forcina A, Clerici D, et al. Sirolimus-based graft-versushost disease prophylaxis promotes the in vivo expansion of regulatory $\mathrm{T}$ cells and permits peripheral blood stem cell transplantation from haploidentical donors. Leukemia. 2015;29(2):396-405. 
13. Hester J, Schiopu A, Nadig SN, Wood KJ. Low-dose rapamycin treatment increases the ability of human regulatory $\mathrm{T}$ cells to inhibit transplant arteriosclerosis in vivo. Am J Transplant. 2012;12(8):2008-2016.

14. Zeiser R, Leveson-Gower DB, Zambricki EA, et al. Differential impact of mammalian target of rapamycin inhibition on CD4+CD25+Foxp3+ regulatory $T$ cells compared with conventional CD4+ T cells. Blood. 2008;111(1):453-462.

15. Baron F, Humblet-Baron S, Ehx G, et al. Thinking out of the boxnew approaches to controlling GVHD. Curr Hematol Malig Rep. 2014;9(1):73-84.

16. Lutz M, Mielke S. New perspectives on the use of mTOR inhibitors in allogeneic haematopoietic stem cell transplantation and graftversus-host disease. Br J Clin Pharmacol. 2016;82(5):1171-1179.

17. Ehx G, Somja J, Warnatz $\mathrm{H}-\mathrm{J}$, et al. Xenogeneic graft-versus-host disease in humanized NSG and NSG-HLA-A2/HHD mice. Front Immunol. 2018;9:1943.

18. Ehx G, Fransolet G, de Leval L, etal. Azacytidine prevents experimental xenogeneic graft-versus-host disease without abrogating graftversus-leukemia effects. Oncoimmunology. 2017;6(5):e1314425.

19. Sondergaard $\mathrm{H}, \mathrm{Kvist} \mathrm{PH}, \mathrm{Haase} \mathrm{C}$. Human T cells depend on functional calcineurin, tumour necrosis factor-alpha and CD80/CD86 for expansion and activation in mice. Clin Exp Immunol. 2013;172(2):300-310.

20. King MA, Covassin L, Brehm MA, et al. Human peripheral blood leucocyte non-obese diabetic-severe combined immunodeficiency interleukin-2 receptor gamma chain gene mouse model of xenogeneic graft-versus-host-like disease and the role of host major histocompatibility complex. Clin Exp Immunol. 2009;157(1):104-118.

21. Battaglia M, Stabilini A, Roncarolo MG. Rapamycin selectively expands CD4+CD25+FoxP3+ regulatory $\mathrm{T}$ cells. Blood. 2005;105(12):4743-4748.

22. Hippen KL, Merkel SC, Schirm DK, et al. Generation and largescale expansion of human inducible regulatory $T$ cells that suppress graft-versus-host disease. Am J Transplant. 2011;11(6):1148-1157.

23. Liston A, Gray DH. Homeostatic control of regulatory T cell diversity. Nat Rev Immunol. 2014;14(3):154-165.

24. Humblet-Baron S, Franckaert D, Dooley J, et al. IL-2 consumption by highly activated CD8 T cells induces regulatory T-cell dysfunction in patients with hemophagocytic lymphohistiocytosis. J Allergy Clin Immunol. 2016;138(1):200-209.e8.

25. Rochman Y, Spolski R, Leonard WJ. New insights into the regulation of $\mathrm{T}$ cells by gamma(c) family cytokines. Nat Rev Immunol. 2009;9(7):480-490.

26. Barata JT, Silva A, Abecasis M, Carlesso N, Cumano A, Cardoso AA. Molecular and functional evidence for activity of murine IL-7 on human lymphocytes. Exp Hematol. 2006;34(9):1133-1142.

27. Slavik JM, Lim DG, Burakoff SJ, Hafler DA. Uncoupling p70(s6) kinase activation and proliferation: rapamycin-resistant proliferation of human CD8(+) T lymphocytes. J Immunol. 2001;166(5):3201-3209.

28. Boyman O, Sprent J. The role of interleukin-2 during homeostasis and activation of the immune system. Nat Rev Immunol. 2012;12(3):180-190.

29. Nunes NS, Kanakry CG. Mechanisms of graft-versus-host disease prevention by post-transplantation cyclophosphamide: an evolving understanding. Front Immunol. 2019;10:2668.

30. Gattinoni L, Klebanoff CA, Restifo NP. Paths to stemness: building the ultimate antitumour T cell. Nat Rev Cancer. 2012;12(10):671-684.

31. Yamashita K, Choi U, Woltz PC, et al. Severe chronic graft-versushost disease is characterized by a preponderance of $\mathrm{CD} 4(+)$ effector memory cells relative to central memory cells. Blood. 2004;103(10):3986-3988.

32. Khandelwal P, Lane A, Chaturvedi V, et al. Peripheral blood CD38 bright CD8+ effector memory $T$ cells predict acute graft-versushost disease. Biol Blood Marrow Transplant. 2015;21(7):1215-1222.

33. Loschi M, Porcher R, Peffault de Latour R, et al. High number of memory $t$ cells is associated with higher risk of acute graft-versus-host disease after allogeneic stem cell transplantation. Biol Blood Marrow Transplant. 2015;21(3):569-574.

34. Alho AC, Kim HT, Chammas MJ, et al. Unbalanced recovery of regulatory and effector $\mathrm{T}$ cells after allogeneic stem cell transplantation contributes to chronic GVHD. Blood. 2016;127(5):646-657.

35. Chen BJ, Cui X, Sempowski GD, Liu C, Chao NJ. Transfer of allogeneic CD62L- memory T cells without graft-versus-host disease. Blood. 2004;103(4):1534-1541.

36. Calastretti A, Rancati F, Ceriani MC, Asnaghi L, Canti G, Nicolin A. Rapamycin increases the cellular concentration of the $\mathrm{BCL}-2$ protein and exerts an anti-apoptotic effect. Eur J Cancer. 2001;37(16):2121-2128.

37. Amarnath S, Flomerfelt FA, Costanzo CM, et al. Rapamycin generates anti-apoptotic human Th1/Tc1 cells via autophagy for induction of xenogeneic GVHD. Autophagy. 2010;6(4):523-541.

38. Fowler DH. Rapamycin-resistant effector T-cell therapy. Immunol Rev. 2014;257(1):210-225.

39. Slavik JM, Lim DG, Burakoff SJ, Hafler DA. Rapamycin-resistant proliferation of CD8+ T cells correlates with p27kip1 down-regulation and bcl-xL induction, and is prevented by an inhibitor of phosphoinositide 3-kinase activity. J Biol Chem. 2004;279(2):910-919.

40. Kwon TK, Buchholz MA, Ponsalle P, Chrest FJ, Nordin AA. The regulation of p27Kip1 expression following the polyclonal activation of murine GO T cells. J Immunol. 1997;158(12):5642-5648.

41. Kawamata S, Sakaida H, Hori T, Maeda M, Uchiyama T. The upregulation of p27Kip1 by rapamycin results in $\mathrm{G} 1$ arrest in exponentially growing T-cell lines. Blood. 1998;91(2):561-569.

42. Gesbert F, Moreau JL, Theze J. IL-2 responsiveness of CD4 and CD8 lymphocytes: further investigations with human IL-2Rbeta transgenic mice. Int Immunol. 2005;17(8):1093-1102.

43. Li WQ, Jiang Q, Aleem E, Kaldis P, Khaled AR, Durum SK. IL-7 promotes T cell proliferation through destabilization of p27Kip1. J Exp Med. 2006;203(3):573-582.

44. Foley JE, Jung U, Miera A, et al. Ex vivo rapamycin generates donor Th2 cells that potently inhibit graft-versus-host disease and graftversus-tumor effects via an IL-4-dependent mechanism. J Immunol. 2005;175(9):5732-5743.

45. Blazar BR, Taylor PA, Panoskaltsis-Mortari A, Vallera DA. Rapamycin inhibits the generation of graft-versus-host disease- and graftversus-leukemia-causing $T$ cells by interfering with the production of Th1 or Th1 cytotoxic cytokines. J Immunol. 1998;160(11):5355-5365.

46. Noviello M, Manfredi F, Ruggiero E, et al. Bone marrow central memory and memory stem T-cell exhaustion in AML patients relapsing after HSCT. Nat Commun. 2019;10(1):1065.

47. Hua H, Kong Q, Zhang H, Wang J, Luo T, Jiang Y. Targeting mTOR for cancer therapy. J Hematol Oncol. 2019;12(1):71.

48. Geissler EK, Schlitt HJ, Thomas G. mTOR, cancer and transplantation. Am J Transplant. 2008;8(11):2212-2218.

49. Ehx G, Hannon M, Beguin Y, Humblet-Baron S, Baron F. Validation of a multicolor staining to monitor phosphoSTAT5 levels in regulatory T-cell subsets. Oncotarget. 2015;6(41):43255-43266.

50. Shatrova AN, Mityushova EV, Vassilieva IO, et al. Time-Dependent Regulation of IL-2R alpha-chain (CD25) expression by TCR signal strength and IL-2-induced STAT5 signaling in activated human blood T lymphocytes. PLoS One. 2016;11(12):e0167215.

51. Strauss L, Czystowska M, Szajnik M, Mandapathil M, Whiteside TL. Differential responses of human regulatory T cells (Treg) and effector T cells to rapamycin. PLoS One. 2009;4(6):e5994.

52. Wang C, Yi T, Qin L, et al. Rapamycin-treated human endothelial cells preferentially activate allogeneic regulatory T cells. J Clin Invest. 2013;123(4):1677-1693.

53. Sandmaier BM, Kornblit B, Storer BE, et al. Addition of sirolimus to standard cyclosporine plus mycophenolate mofetil-based graftversus-host disease prophylaxis for patients after unrelated nonmyeloablative haemopoietic stem cell transplantation: a multicentre, randomised, phase 3 trial. Lancet Haematol. 2019;6(8):e409-e418. 
54. Fransolet G, Ehx G, Somja J, et al. Azacytidine mitigates experimental sclerodermic chronic graft-versus-host disease. J Hematol Oncol. 2016;9(1):53.

55. Boucault L, Lopez Robles M-D, Thiolat A, et al. Transient antibody targeting of CD45RC inhibits the development of graft-versus-host disease. Blood Adv. 2020;4(11):2501-2515.

\section{SUPPORTING INFORMATION}

Additional supporting information may be found online in the Supporting Information section.
How to cite this article: Ehx G, Ritacco C, Hannon M, et al. Comprehensive analysis of the immunomodulatory effects of rapamycin on human $\mathrm{T}$ cells in graft-versus-host disease prophylaxis. Am J Transplant. 2021;21:2662-2674. https://doi. org/10.1111/ajt.16505 